\title{
Emotional declarative memory assessment of patients with mesial temporal lobe epilepsy and patients submitted to mesial temporal lobectomy
}

\author{
Lara De Vecchi Machado1', Jean Edith Frank², Carlos Tomaz ${ }^{3}$
}

\begin{abstract}
Epileptic seizures generate cognitive and behavioral impacts in individuals who suffer from epilepsy. Declarative memory is one of the cognitive functions that can be affected by epileptic seizures. The main objective of this work was to investigate neurocognitive function, especially the emotional working memory of patients with unilateral mesial temporal lobe epilepsy, and that of patients submitted to unilateral mesial temporal lobectomy. A face recognition test that can simultaneously recruit the frontal lobe (working memory) and mesial temporal lobe (emotional memory) was used to investigate emotional working memory. Our findings showed that the epilepsy factor significantly compromised the performance in the emotional memory test. On the other hand, surgical removal of the epileptic focus promoted an improvement in the emotional working memory of these patients, in addition to the significantly decrease in the number of seizures.
\end{abstract}

Key words: emotional memory, epilepsy, temporal lobectomy.

Avaliação da memória declarativa emocional em pacientes com epilepsia temporal mesial e pacientes submetidos à lobectomia temporal mesial

\section{RESUMO}

Crises epilépticas geram impactos comportamentais e cognitivos em indivíduos que sofrem de epilepsia. Uma das funções cognitivas que pode ser afetada pelas crises epilépticas é a memória declarativa. O objetivo do nosso estudo foi investigar funções cognitivas, especialmente a memória operacional emocional de pacientes com epilepsia temporal mesial unilateral e pacientes submetidos a lobectomia temporal mesial unilateral. Para investigar a memória operacional emocional foi utilizado um teste de reconhecimento de faces que pode recrutar simultaneamente o lobo frontal (memória operacional) e o lobo temporal mesial (memória emocional). Nossos resultados demonstram que o fator epilepsia compromete de forma significativa o desempenho no teste de memória emocional. Por outro lado, a remoção cirúrgica do foco epiléptico promoveu uma melhora na memória emocional desses pacientes, além de diminuir o número de crises.

Palavras-chave: memória emocional, epilepsia, lobectomia temporal.

\section{Correspondence}

Carlos Tomaz

Laboratory of Neurosciences and Behavior Institute of Biology, University of Brasília Campus Universitário Darcy Ribeiro Asa Norte 70910-900 Brasília DF- Brasil

E-mail: ctomaz@unb.br

Received 30 October 2009

Received in final form 23 March 2010

Accepted 31 March 2010
Declarative memory is a long-term memory system relating to conscious recollection of facts and events of an individual's life. When emotional information combines with evoked declarative memo- ry, a subtype of declarative memory forms: the emotional declarative memory or emotional memory ${ }^{1}$.

When activated, the emotional state interferes with memory consolidation. Emo-

${ }^{1} \mathrm{PhD}$ Candidate, Physiotherapist, Graduate Program in Health Sciences, Faculty of Health Sciences, University of Brasília (UnB), Brasília DF, Brazil; ${ }^{2} \mathrm{PhD}$, Psychologist, Laboratory of Neurosciences and Behavior, Institute of Biology, UnB; ${ }^{3} \mathrm{PhD}$, Full Professor, Laboratory of Neurosciences and Behavior, Institute of Biology, UnB. 
tional events are probably codified in a way that may become resistant to extinction ${ }^{1-9}$. This is due to specific neural and hormonal mechanisms that modulate memory for emotional stimuli, ${ }^{3,10,11}$. These mechanisms seem to operate in part by recruiting general cognitive mechanisms such as attention, and in part by self-mechanisms activated by emotion ${ }^{10,11}$.

Many studies that assessed emotional memory have raised the possibility that the neural substrate of emotional memory extends to neuronal circuits within the mesial region of the temporal lobe $e^{1,8,12-14}$, essentially the amygdale and hippocampus.

Neuroimaging studies have provided important convergence between the findings from studies on electrical activity, drugs, lesions and neuropsychological studies, inferring that the amygdale and other limbic areas are involved not only in the acquisition and consolidation of emotional memory but also in its elicitation ${ }^{8,10,11,15}$. However, the role of each hemisphere and the differences in gender-related function of the amygdale have not been fully clarified.

Epilepsy is a disorder of the nervous system that abruptly interferes in behavior, perception, movement, conscience and/or in other cortical functions. In turn, these changes lead to inability to adapt to the environment, hence compromising such individuals' quality of life. Temporal lobe epilepsy (TLE) is the most common type of epilepsy, since the temporal lobe is the most epileptogenic of the cerebral lobes and the most difficult one to treat pharmacologically $y^{16,17}$.

Studies have shown that epilepsy can impair memory acquisition and storage ${ }^{18}$. Although cognitive deficits in epileptic patients are very frequent, the pattern and extent of these deficits vary greatly. This variation is due to a number of factors, such as: [a] location and extent of the dysfunctional area or brain injury; [b] anticonvulsant medication used; [c] age at seizure onset and epilepsy duration and [d] seizure type and frequency $y^{18-20}$.

Therefore, the main objective of the present work was to investigate the neurocognitive function of patients with unilateral mesial temporal lobe epilepsy, especially assessing the declarative memory subtype. For this purpose, the working memory test Delay-non-Matching-to-Sample (DNMTS) with emotional content was used.

\section{METHOD}

\section{Subjects}

The patients, referred by physicians at the Neurological Institute of Goiânia, were properly diagnosed and presented normal intellectual capacity according to the WAIS-III test for neuropsychological assessment. The research project was approved by the Research Ethics Committee of the Federal University of Goiás. All subjects were informed about the research procedures and signed a free and informed consent form.

The subjects were divided into three study groups: control group, pre-surgery group and post-surgery group. The control group consisted of 21 healthy subjects (10 women and 11 men); the pre-surgery group consisted of 20 subjects with unilateral mesial temporal lobe epilepsy. The epileptic focus was identified by EEG-video monitoring and magnetic resonance (MR). This group included 10 women (five with epileptic focus on the left and five on the right) and 10 men (six with epileptic focus on the left and four on the right). The post-surgery group consisted of 23 subjects in the late postoperative period after mesial temporal lobectomy, as confirmed by magnetic resonance. This group included 12 women (six with unilateral left lobectomy and six with unilateral right lobectomy) and 11 men (five with left lobectomy and six with right lobectomy) (Table 1).

The neurocognitive test was applied to the three groups so that the results of each group could be compared with the other two. The computer was a Toshiba laptop, model Satellite M55-S135, with a 14-inch widescreen. The subject remained at roughly $50 \mathrm{~cm}$ away from the screen.

\section{Inclusion criteria}

Group 1 - Control - Individuals of both genders, aged 16 to 55 years who were not taking anti-anxiety or antidepressive drugs, without any identified neurological disease, and who reported being right-handed.

Group 2 - Pre-surgery - Epileptic patients (both genders, aged 16 to 55 years) properly diagnosed by magnetic resonance, electroencephalogram (EEG) and/or video monitoring with unilateral mesial temporal lobe epilepsy, without clinical signs of drug intoxication, who had not

Table 1. Demographics.

\begin{tabular}{|c|c|c|c|c|c|c|}
\hline \multirow[b]{2}{*}{ Group } & \multirow[b]{2}{*}{ Age (mean $\pm S D$ ) } & \multirow[b]{2}{*}{ Disease duration (mean $\pm S D$ ) } & \multicolumn{2}{|c|}{ Gender } & \multicolumn{2}{|c|}{ Lateralization } \\
\hline & & & Female & Male & Left & Right \\
\hline Control & $35.05(2.54)$ & & 10 & 11 & & \\
\hline Pre-surgery & $38.25(2.64)$ & $26.80(2.64)$ & 10 & 10 & 11 & 9 \\
\hline Post-surgery & $34.43(1.82)$ & $26.87(1.88)$ & 12 & 11 & 11 & 12 \\
\hline
\end{tabular}

SD: standard deviation. 
had a seizure during the 24 hours preceding the tests, and who reported being right-handed.

Group 3 - Post-surgery - Patients (both genders, aged 16 to 55 years) with a magnetic resonance report proving that they had undergone a unilateral temporal lobectomy, including hippocampus and amygdale. The surgical technique used in the Neurological Institute of Goiania is the Spencer technique, developed in Yale University, which resects the hippocampus and amygdale as much as possible. The patients did not present clinical signs of intoxication and had not had a seizure during the 24 hours preceding the tests. They reported being right-handed.

\section{Neurocognitive assessment}

The emotional working memory test Delay-nonMatching-to-Sample (DNMTS) is a computer-based working memory test that also assesses the emotional memory of the individual. Therefore, it is believed that this test is capable of recruiting the frontal lobe (working memory) and the mesial temporal lobe (emotional memory) simultaneously.

The first test was developed by Ekman \& Wallace (1976) and was called Pictures of Facial Affect; it presented seven different emotional facial expressions and was widely used in the literature on emotion. In order to increase the number of stimuli to be used in the test, the Neurosciences and Behavior Laboratory of UNB, in 2003, developed a test with eight different emotional facial expressions (negative surprise, positive surprise, fear, anger, happiness, disgust, neutral and sadness) obtained by taking facial pictures of actors. The test consists of a battery of stimuli such that each battery has eight pictures of the same actor with the facial expressions listed above. This ensures that the recognition is based on the facial expression alone.

The DNMTS consisted of presenting a stimulus [A] followed by an eight-second break and the presentation of two stimuli [A and B], of which one is repeated [A]. The subject has to choose the new stimulus [B].

The test consisted of a battery of two geometric stimuli, for the subject to learn, and two batteries with eight different facial expressions of two actors, one male and one female. Each stimulus was presented in a $5 \mathrm{~cm} \times 5 \mathrm{~cm}$ square.

The Sysmem software (Lab. Neuroscience \& Behavior, University of Brasília) was used for the DNMTS test. It enabled manipulation of many parameters and generated automatic spreadsheets after each test, containing the response time for each attempt, the number of errors and the number of pictures.

\section{Statistical analyses}

The data were organized and analyzed using Excel $^{\circ}$ 2003 and SPSS 13 (Statistical Package for the Social Sciences, Chicago, IL, USA) for Windows ${ }^{\circ}$.
Firstly, the mean reaction time of each attempt and the percentage of correct choices made by each individual were calculated. These data were used in the analysis models.

One-, two- and three-way univariate analyses of variance (ANOVA) were used, covering the factors Group, Gender and Lateralization together or alone. The post hoc analyses were performed in accordance with the Bonferroni method for adjusting the statistical significance level.

All tests were two-tailed, and statistical significance was set as $\mathrm{p} \leq 0.05$.

\section{RESULTS}

\section{Descriptive analysis of the groups}

Disease durations in the pre- and post-surgery groups were not statistically different $(\mathrm{p}=0.983)$ (Table 2 ). Regarding the time elapsed since the last seizure, the post-surgery group presented a seizure interval significantly greater than in the pre-surgery group $(\mathrm{p}<0.001)$ (Table 3$)$. The mean time elapsed since surgery was 14.1 (2.09) months.

\section{Comparison of the factor \\ Epilepsy vs. Gender $(2 \times 2)$}

In the DNMTS test, the factor Epilepsy had a significant effect on the variables of reaction time $\left(\mathrm{F}_{1,60=} 5.773\right.$, $\mathrm{p}=0.019)($ Fig $1 \mathrm{~A})$ and percentage of correct answers

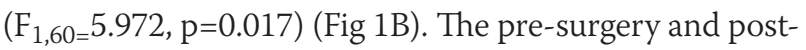
surgery group set, representing the factor Epilepsy, had a greater reaction time $(\mathrm{p}=0.019)$ and a smaller percentage of correct answers $(\mathrm{p}=0.017)$ than did the control without epilepsy. The factor Gender and the interaction Epilepsy versus Gender did not have significant statistical effects on the two variables studied ( $\mathrm{Fs}<0.094, \mathrm{ps}>0.760)$.

\section{Comparison between Groups and Gender $(3 \times 2)$}

The factor Group presented a significant effect on mean reaction time in the DNMTS test $\left(\mathrm{F}_{2,58=} 3.608\right.$, $\mathrm{p}=0.033)($ Fig 2A). The factor Gender and the interaction

Table 2. Mean disease duration and mean time elapsed since the last seizure.

\begin{tabular}{lcc}
\hline Group & Disease duration (years) & Last seizure (days) \\
\hline Pre-surgery & $26.8\left(2.64^{*}\right)$ & $6.75\left(1.49^{*}\right)$ \\
Post-surgery & $26.87\left(1.88^{*}\right)$ & $417.87\left(58.76^{*}\right)$ \\
\hline
\end{tabular}

*Standard deviation.

Table 3. Mean time elapsed since surgery.

\begin{tabular}{cc}
\hline Sex & Time surgery (months) \\
\hline Female & $16.75\left(1.89^{*}\right)$ \\
Male & $11.45\left(2.28^{*}\right)$ \\
\hline
\end{tabular}

*Standard deviation. 


\section{A}
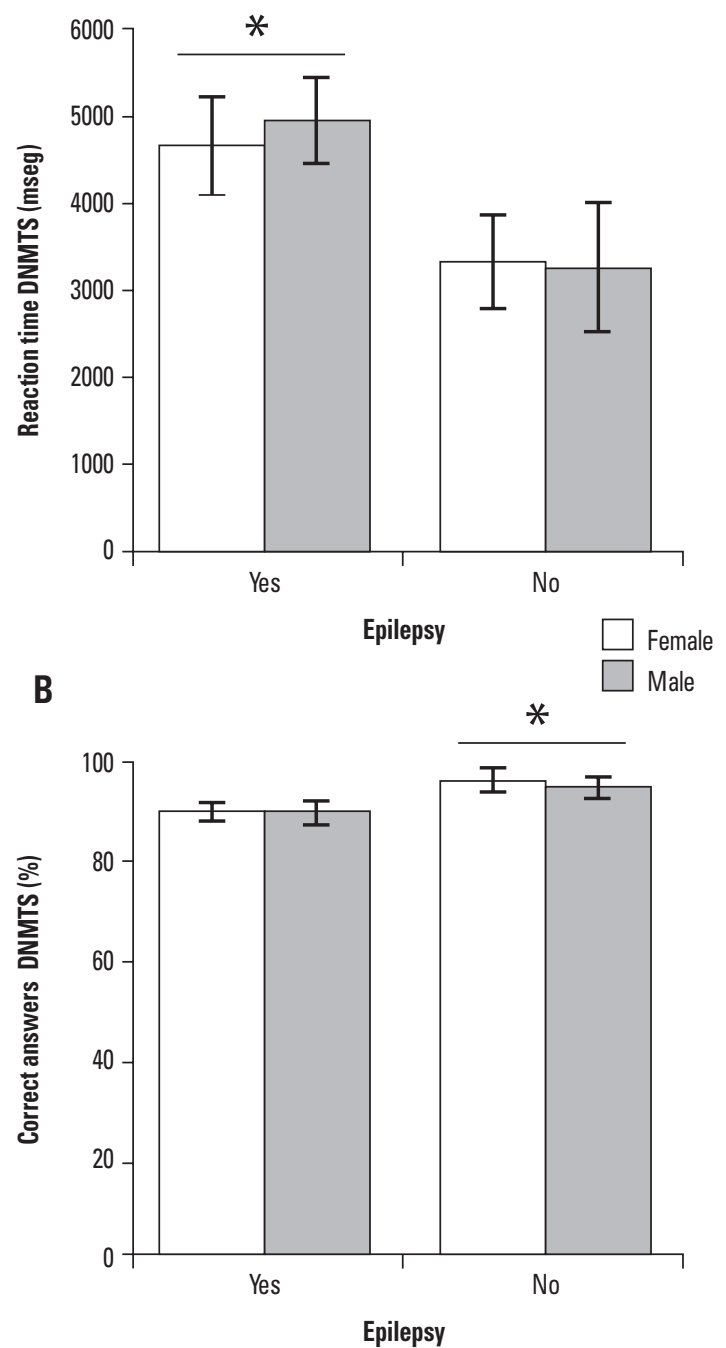

Fig 1. [A] Results from the pre-surgery and post-surgery groups, representing the factor Epilepsy. There was a greater reaction time in these groups than that of the control group ( $p=0.019)$. [B] Results from the pre-surgery and post-surgery groups, representing the factor Epilepsy. There was a smaller percentage of correct answers in these groups than in the control group $(p=0.017)$.

Group versus Gender did not present significant effects on this variable $(\mathrm{Fs}<0.824$, ps $>0.443)$. The multiple comparison procedure showed that the difference was in the comparison between the groups Control and Pre-surgery $(\mathrm{p}=0.033)$. Analysis of correct answer percentages in the DNMTS test did not elicit differences that could be attributed to the factors Group or Gender, or to their interaction ( Fs $<3.050$, ps $>0.054)$.

\section{Comparison between Group vs. Gender vs. Lateralization $(2 \times 2 \times 2)$}

Note - For this analysis model, it was not possible to use the Control group, since there were no data regarding its lateralization.
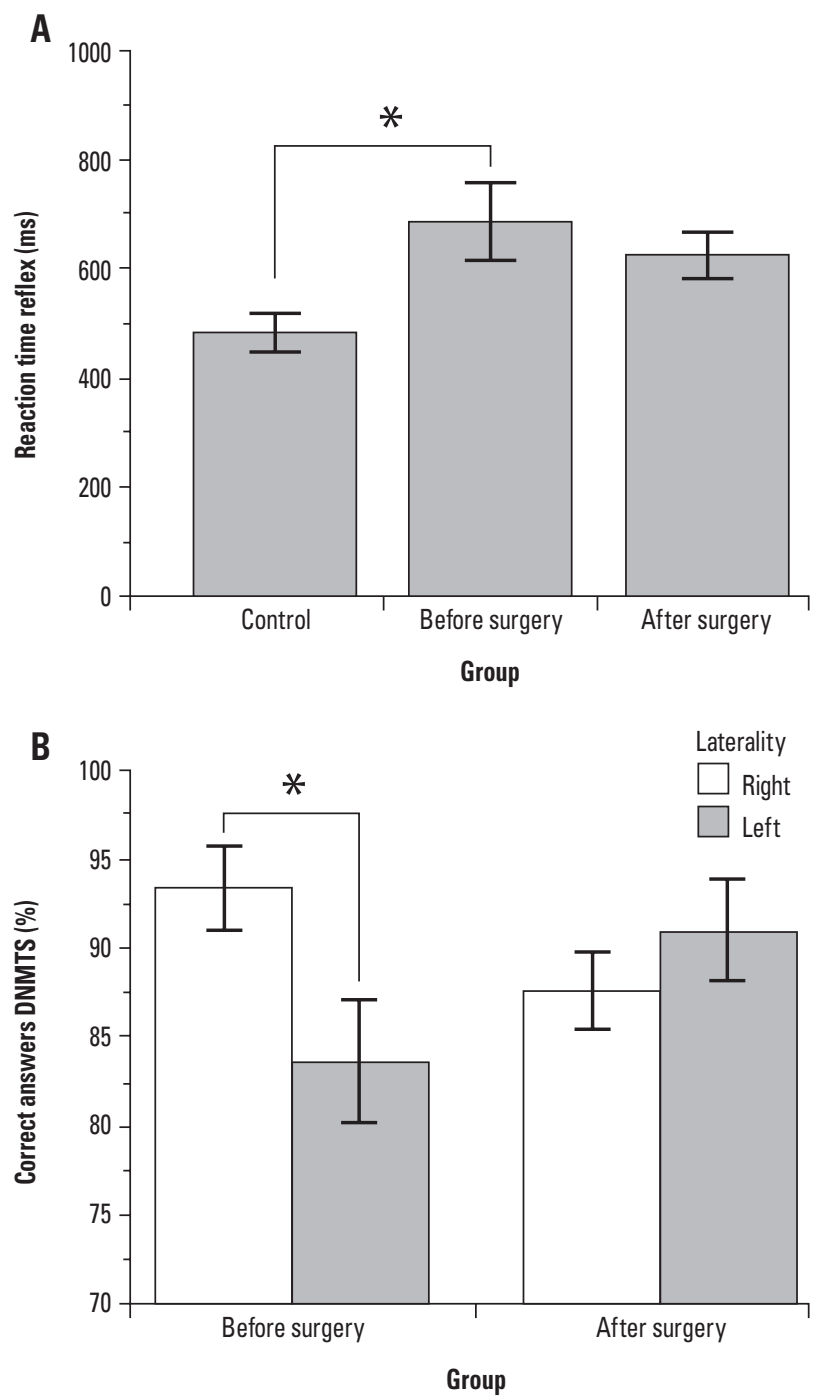

Fig 2. $[A]$ The pre-surgery group showed a significantly greater reaction time than did the control group $(p=0.033)$. [B] In the presurgery group, subjects with lesions on the left side showed a significantly smaller percentage of correct answers than did those with lesions on the right side $(p=0.028)$.

In the DNMTS test, neither of the factors nor the interaction of these factors presented a significant effect on mean reaction time ( $\mathrm{Fs}>1.869$, $\mathrm{ps}>0.179)$. Regarding the percentage of correct answers in the test, the analysis showed that the factors Group, Gender, Lateralization, and the interactions Group $\times$ Gender, Gender $\times$ Lateralization and Group $\times$ Gender $\times$ Lateralization did not have a significant effect on the results ( $\mathrm{Fs}<1.326$, ps $>0.256$ ). The interaction Group $\times$ Lateralization showed a statistically significant effect on the variable percentage of correct answers $\left(\mathrm{F}_{1,35}=5.235, \mathrm{p}=0.028\right)$ (Fig $\left.2 \mathrm{~B}\right)$. In the presurgery group, subjects with epileptic focus in the left brain hemisphere had a smaller percentage of correct answers than did those with focus in the right. This difference was not observed after surgery. 

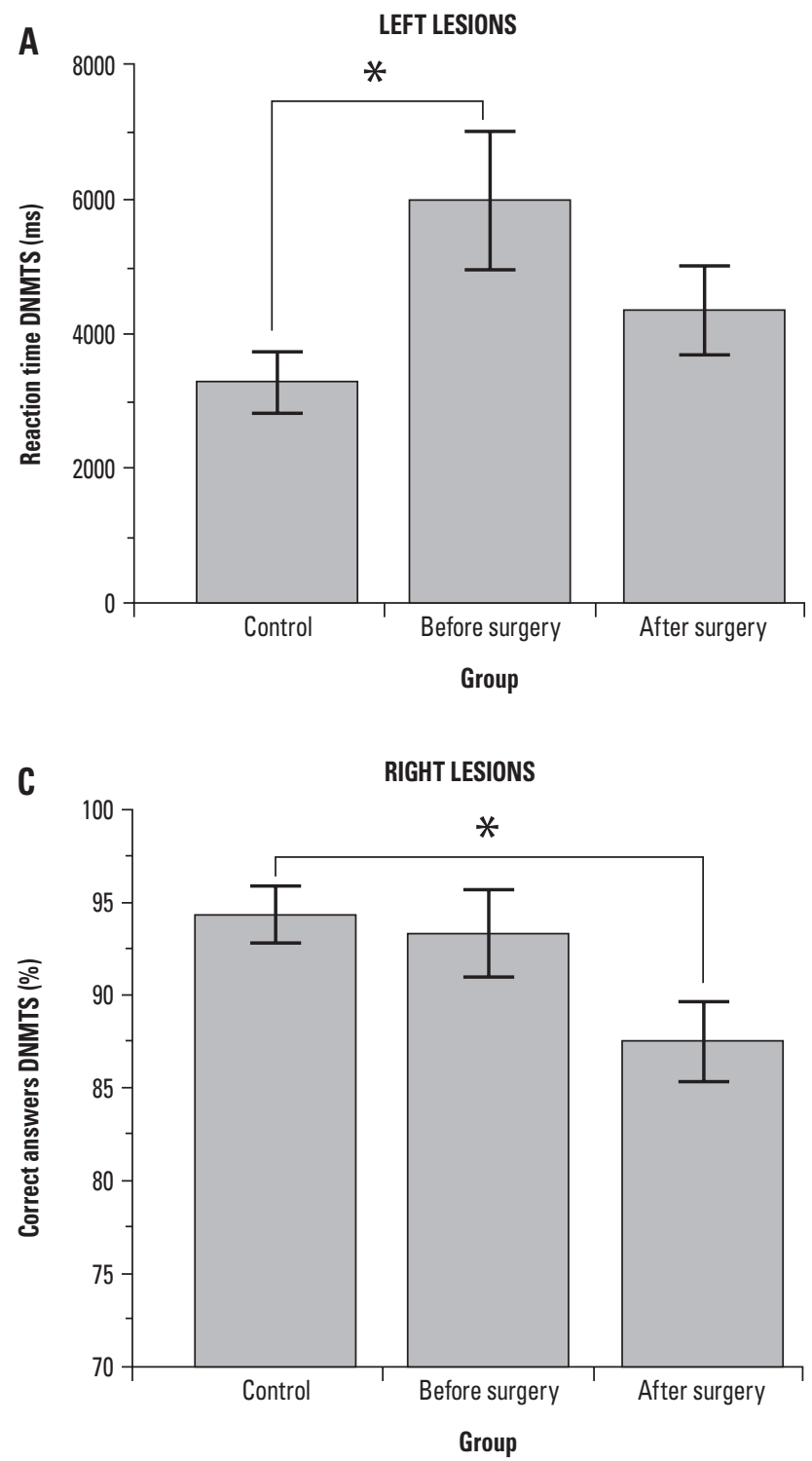

\section{Comparison of Group vs.}

\section{Gender vs. Lateralization}

The control group was included after two ANOVA analyses, and comparison of all the dependent variables (reaction times and percentage of correct answers) were carried out for the groups. One of the ANOVA analyses compared the subjects with lesions in the left hemisphere with the control group; the other ANOVA compared subjects with lesions in the right hemisphere with the control group.

The comparison between subjects with lesion in the left and control subjects showed that the factor Group had statistically significant effects on the variables reaction time in DNMTS $\left(\mathrm{F}_{2,40}=4.309, \mathrm{p}=0.020\right)(\mathrm{Fig} 3 \mathrm{~A})$ and percentage of correct answers in DNMTS $\left(\mathrm{F}_{2,40}=5.356\right.$, $\mathrm{p}=0.009)$ (Fig $3 \mathrm{~B})$. The multiple comparison procedure showed that the pre-surgery group had higher response

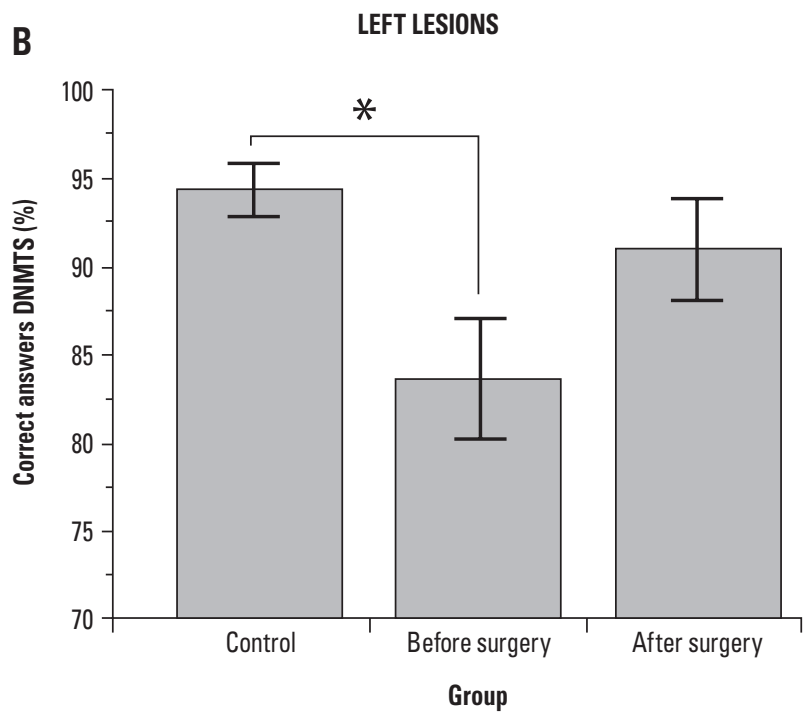

Fig 3. $[A]$ The pre-surgery group showed a significantly greater reaction time in comparison with the control group $(p=0.020)$. [B] The pre-surgery group showed a significantly smaller percentage of correct answers in comparison with the control group $(p=0.009)$. [C] The control group showed a significantly greater percentage of correct answers in comparison with the post-surgery group $(p=0.034)$.

times in the DNMTS test and lower percentages of correct answers than the control group (ps<0.017).

The comparison between subjects with lesion in the right and control subjects showed that the factor Group had a significant effect on the percentage of correct answers in DNMTS $\left(\mathrm{F}_{2,39}=3.699, \mathrm{p}=0.034\right)$. The multiple comparison procedure showed statistically significant differences between the control group and the post-surgery group ( $\mathrm{p}=0.034)$ (Fig $3 \mathrm{C})$ : the control group had a higher percentage of correct answers than the post-surgery group. Statistically significant differences among the groups were not found for the other variables $\left(\mathrm{Fs}_{2,39}<2.370\right.$, ps $\left.>0.106\right)$.

\section{DISCUSSION}

The main objective of the present study was to investigate the neurocognitive functions of patients with unilat- 
eral mesial temporal lobe epilepsy, in particular the emotional working memory.

One of the results indicated that the factor epilepsy significantly compromised the performance in the emotional memory test, since the pre- and post-surgery groups, representing the factor Epilepsy, had a significant effect on variable reaction time and percentage of correct answers in comparison with the control group. This finding has been reported in the literature by some groups, stating that seizures can generate cognitive and behavioral impacts in individuals with epilepsy. Furthermore, one of the cognitive functions that can be affected by seizures is the declarative memory ${ }^{18-21}$.

No significant difference regarding the reaction time and percentage of correct answers in the DNMTS test was found between the pre- and post-surgery groups. However, the present results show significantly higher reaction times in the DNMTS test for the pre-surgery group, compared with the control group. Additionally, the post-surgery group presented only an insignificant performance deficit in the emotional memory test in comparison with the control group. These results may lead to the inference that surgical removal of the epileptic focus improved the declarative memory of these patients, especially the emotional working memory.

This finding corroborates those of other studies reported in the literature, such as that of Aldenkamp and Bodde $^{21}$. These authors concluded from a review on behavior, cognition and epilepsy that the origin of cognitive or behavioral deficits was frequently related to structural brain damage caused by seizures. Seizures are capable of inducing progressive cellular and metabolic changes that are associated with neuronal hippocampal loss, neurogenesis and synaptic reorganization. The main clinical characteristic of mesial temporal lobe epilepsy is that, in most cases, the seizures become refractory to drugs, and therefore the best treatment is to remove the epileptogenic focus surgically ${ }^{19,20}$.

Another important finding was the significant reduction in the number of seizures in the post-surgery group in comparison with the pre-surgery group. This seems to be another good reason to remove the epileptic focus, since surgery directly influences the control of epilepsy and may lead to improved cognition in the long run, particularly in declarative memory. The literature shows that seizure frequency is one of the main factors for cognitive deficits found in patients with epilepsy ${ }^{18-26}$.

The results from the present work did not show a significant difference in performance in the emotional memory tests between genders. This finding suggests that there may not be any association between lateralization and gender. Similar results have been observed in other studies, such as that of Frings et al. ${ }^{27}$ who investigated the lateralization of hippocampal activation during memory tests related to the mesial temporal lobe, in patients with unilateral epilepsy of that same lobe with functional magnetic resonance. These authors did not find any relationship between hippocampal activity and gender, but they found a relationship between hippocampal activity and the side of the epileptic focus.

Recently, other studies have indicated the existence of gender-associated lateralization of the amygdale that modulated emotional memory, thus suggesting that the right amygdale in males and the left amygdale in females are responsible for modulating emotional memory ${ }^{1,8,11,28}$.

When only lateralization and group were considered, there was a significant difference between the pre-surgery group and the control group regarding performance in the emotional memory test among subjects with lesions in the left hemisphere. The pre-surgery subjects with lesion on the left side presented significantly worse results both for the reaction time and for the percentage of correct answers in the DNMTS test, compared with the control group. This poorer performance was also significant within the pre-surgery group when the side of the lesion was compared. Subjects with the lesion on the left side presented significantly higher reaction times in the DNMTS test than did those with the lesion on the right side.

This greater reaction time in subjects with lesions on the left side is in agreement with the hypothesis proposed by Frank and Tomaz ${ }^{13}$, i.e. that the left amygdale has an important role in the process of emotional information acquisition and therefore patients with epilepsy on the left would have a worse performance in the DNMTS test. This test investigates emotional working memory, and the acquisition phase and attention status are essential for good performance. However, other studies that attempted to elucidate the difference between the roles of the right and left amygdales in the formation of emotional memories are still inconclusive $\mathrm{e}^{1,13}$.

In the post-surgery group, subjects who underwent right mesial temporal lobectomy presented a lower number of correct answers in the motional memory test (DNMTS) than did the control group. This result corroborates the findings of Frank and Tomaz from a clinically similar group $^{13}$, thus showing that the right hemisphere is more specialized for processing visual stimuli of emotional nature, since the emotional stimuli used in the test are visual ${ }^{13,28-30}$.

Another interesting aspect of the present work is the use of an innovative test aiming to investigate emotional working memory, through recruiting the frontal lobe (working memory) and the mesial temporal lobe (emotional memory) simultaneously. Thus, this work may contribute towards recent studies that try to elucidate the role of the mesial temporal lobe on working memory when exposed to emotional stimuli. 


\section{REFERENCES}

1. Tomaz C, Frank JE, Conde C. Integrative function of the amygdala in emotional memory storage. Int Congr Ser 2003;1250:335-346.

2. Hwang DY, Golby AJ. The brain basis for episodic memory: insights from functional MRI, intracranial EEG, and patients with epilepsy. Epilepsy Behav 2006;8:115-126

3. Cahill L, McGaugh JL. A novel demonstration of enhanced memory associated with emotional arousal. Conscious Cogn 1995;4:410-421.

4. Adolphs R, Cahill L, Schul R, Babinsky R. Impaired declarative memory for emotional material following bilateral amygdala damage in humans. Learn Mem 1997:4:291-300.

5. Phelps EA, LaBar KS, Spencer DD. Memory for emotional words following unilateral temporal lobectomy. Brain Cogn 1997;35: 85-109.

6. Dalgleish T. The emotional brain. Nat Rev Neurosci 2004; 5:583-589.

7. Brierley B, Medford N, Shaw P, David AS. Emotional memory and perception in temporal lobectomy patients with amygdala damage. J Neurol Neurosurg Psychiatry 2004;75:593-599.

8. Dolcos F, LaBar KS, Cabeza R. Remembering one year later: role of the amygdala and the medial temporal lobe memory system in retrieving emotional memories. Proc Natl Acad Sci USA 2005;102:2626-2631.

9. Gasbarri A, Pompili A, Arnone B, et al. Declarative memory retention and emotional stimuli. A study of an Italian sample. Funct Neurol 2005;20: 157-162.

10. Dolan RJ, Lane R, Chua P, Fletcher P. Dissociable temporal lobe activations during emotional episodic memory retrieval. Neuroimage 2000;11: 203-209.

11. Hamann S. Cognitive and neural mechanisms of emotional memory. Trends Cogn Sci 2001:5:394-400.

12. Brewer JB, Moghekar A. Imaging the medial temporal lobe: exploring new dimensions. Trends Cogn Sci 2002;6:217-223.

13. Frank JE, Tomaz C. Lateralized impairment of the emotional enhancement of verbal memory in patients with amygdala-hippocampus lesion. Brain Cogn 2003;52:223-230

14. Baxter L, Spencer B, Kerrigan J. Clinical application of functional MRI for memory using emotional enhancement: deficit and recovery with limbic encephalitis. Epilepsy Behav 2007;11:454-459.

15. Bell B, Giovagnoli A. Recent innovative studies of memory in temporal lobe epilepsy. Neuropsychol Rev 2007;17:455-476

16. Kent GP, Schefft BK, Howe SR, Szaflarski JP, Yeh HS, Privitera MD. The ef- fects of duration of intractable epilepsy on memory function. Epilepsy Behav 2006:9:469-477.

17. Cavazos JE, Cross DJ. The role of synaptic reorganization in mesial temporal lobe epilepsy. Epilepsy Behav 2006;8:483-493.

18. Lah S, Lee T, Grayson S, Miller L. Effects of temporal lobe epilepsy on retrograde memory. Epilepsia 2006;47:615-625.

19. Alessio A, Damasceno BP, Camargo CH, Kobayashi E, Guerreiro CA, Cendes F. Differences in memory performance and other clinical characteristics in patients with mesial temporal lobe epilepsy with and without hippocampal atrophy. Epilepsy Behav 2004;5:22-27.

20. Alessio A, Kobayashi E, Damasceno BP, Lopes-Cendes I, Cendes F. Evidence of memory impairment in asymptomatic individuals with hippocampal atrophy. Epilepsy Behav 2004;5:981-987.

21. Aldenkamp AP, Bodde N. Behaviour, cognition and epilepsy. Acta Neurol Scand 2005;182:19-25.

22. Hernandez MT, Sauerwein HC, Jambaqué I, et al. Attention, memory, and behavioral adjustment in children with frontal lobe epilepsy. Epilepsy Behav 2003;4:522-536.

23. Lagae L. Cognitive side effects of anti-epileptic drugs the relevance in childhood epilepsy. Seizure 2006;15: 235-241.

24. Chaix Y, Laguitton V, Lauwers-Cances $V$, et al. Reading abilities and cognitive functions of children with epilepsy: Influence of epileptic syndrome. Brain Dev 2006:28:122-130.

25. Lutz MT, Helmstaedter C. EpiTrack: tracking cognitive side effects of medication on attention and executive functions in patients with epilepsy. Epilepsy Behav 2005;7:708-714

26. Vingerhoets G. Cognitive effects of seizures. Seizure 2006;15: 221-226.

27. Frings L, Wagner K, Halsband U, Schwarzwald R, Zentner J, Schulze-Bonhage A. Lateralization of hippocampal activation differs between left and right temporal lobe epilepsy patients and correlates with postsurgical verbal learning decrement. Epilepsy Res 2008;78:161-170.

28. Gasbarri A, Arnone B, Pompili A, et al. Sex-related lateralized effect of emotional content on declarative memory: an event related potential study. Behav Brain Res 2006;168:177-184.

29. Campo P, Maestù F, Ortiz T, Capilla A, Fernandez S, Fernandez A. Is medial temporal lobe activation specific for encoding long-term memories? Neurolmage 2005:25:34-42.

30. Chiaravalloti N, Glosser G. Memory for faces dissociates from memory for location following anterior temporal lobectomy. Brain Cogn 2004;54:35-42. 